\title{
Natural Killer Cells are Present in the Normal Human Lung but Are Functionally Impotent
}

\author{
Bruce W. S. Robinson, Paula Pinkston \\ and Ronald G. Crystal \\ Pulmonary Branch, National Institutes of Health, Bethesda,
} Maryland 20205

bstract. The lung is affected by disorders in which natural killer (NK) cells are thought to play an important defensive role. This study, however, demonstrated that normal lung lymphocytes actually express very little NK cell activity $(P<0.001$ compared with blood lymphocytes). This was true independent of the NK-sensitive target used (K562, U937, MOLT-3, or Daudi). This lack of lung lymphocyte NK activity occurred even though the proportions of lymphocytes in the normal lower respiratory tract with the morphology (large granular lymphocytes) and surface antigen markers of NK cells were similar to that of blood $(P>0.5)$. Although normal lung lymphocytes bound to known NK-sensitive targets, they did not lyse these cells $(P$ $<0.001$ compared with blood), which suggested that the lack of lung NK cell activity resulted from a relative inability of lung NK cells to destroy their targets. While the mechanisms of this functional impotence of lung NK cells are not clear, normal human alveolar macrophages and lower respiratory tract epithelial lining fluid exerted a profound suppressive effect on blood NK cell activity $(P<0.001$ for both) by inhibiting their ability to lyse target cells after binding $(P<0.001)$. Though impotent initially, when incubated for $24 \mathrm{~h}$ in medium alone, normal lung lymphocytes demonstrated markedly enhanced NK activity $(P<0.02)$, which suggested that lung NK cells do have the potential to express NK activity. Interleukin-2 (IL-2) further augmented this effect $(P<0.05)$, but gamma interferon did not $(P$

Address reprint requests to Dr. Ronald G. Crystal, National Heart, Lung and Blood Institute, Building 10, Room 6D20, Bethesda, MD 20205.

Received for publication 5 April 1984 and in revised form 7 June 1984.

J. Clin. Invest.

(c) The American Society for Clinical Investigation, Inc.

0021-9738/84/09/0942/09 $\$ 1.00$

Volume 74, September 1984, 942-950
$>0.2$ ). Consistent with this observation, lung lymphocytes from patients with active sarcoidosis, a disease in which lung lymphocytes are spontaneously releasing IL2 , did express NK cell activity $(P<0.01)$. These studies suggest that although NK cells are present in the normal lung, they are functionally inactive, due, at least in part, to local inhibitory influences. In the presence of IL-2, however, lung NK cell activity is expressed, which suggests that lung NK cell activity can be modulated.

\section{Introduction}

Natural killer (NK) ${ }^{1}$ cells represent a subpopulation of lymphocytes capable of lysing target cells without prior sensitization. Since this "natural" killer activity is most evident against neoplastic and virus-infected targets, it is thought that the major in vivo role of NK cells is to provide surveillance against neoplastic cells or those modified by viral infection (1). NK activity can be readily detected in blood of normal individuals and is known to be altered in a variety of disorders (2).

The lung is a major site for both neoplastic disease and viral infections. Since the normal lower respiratory tract contains significant numbers of lymphocytes, and since the normal proportions of lymphocyte subtypes such as $\mathrm{T}$ cells, $\mathrm{T}$ helper cells, and $T$ suppressor cells are similar to blood (3), it is reasonable to hypothesize that $\mathrm{NK}$ activity in the lower respiratory tract is also similar to blood. Surprisingly, the present study demonstrates that for equivalent numbers of lymphocytes, while there are cells present with morphologic, antigenic, and binding characteristics of NK cells, functional lung NK activity is markedly reduced when compared with blood.

While lung NK cells appear to be functionally impotent, it is known that mediators that are released by activated $T$ lymphocytes, such as interleukin-2 (IL-2), can augment NK cell activity (4). In this context, since IL-2 is spontaneously

1. Abbreviations used in this paper: ELF, epithelial lining fluid; FCS, fetal calf serum; IFN $_{\gamma}$, gamma interferon; HBSS, Hanks' balanced salt solution; IL-2, interleukin-2; LGL, large granular lymphocytes; NK, natural killer; SRBC, sheep red blood cells; HNK-1, surface antigen marker. 
released by $T$ cells in the lower respiratory tract in active pulmonary sarcoidosis (5), we hypothesized that active sarcoidosis might be a useful naturally occurring in vivo model to examine whether the presence of IL-2 in the local milieu might be associated with enhancement of lung NK activity. The data demonstrate that this is the case. Furthermore, IL-2 can augment normal lung lymphocyte NK activity in vitro. Thus, while NK cell activity in the normal lung is very low, lung NK cell activity can be modified.

\section{Methods}

Normal study population. Normal individuals $\left(n=22\right.$, age $23 \pm 1 \mathrm{yr},{ }^{2}$ 14 males, 8 females) had normal physical examinations, chest X-rays, and lung function tests. None were taking medications. All were nonsmokers.

Isolation of blood and lung effector cells. Blood mononuclear cells were isolated from heparinized peripheral blood and buffy coat preparations by density gradient centrifugation using lymphocyte separation medium (Litton Bionetics, Kensington, MD). Lung mononuclear cells were obtained using bronchoalveolar lavage as previously described (6). Briefly, a fiberoptic bronchoscope was wedged into a distal segment of the lower respiratory tract and 5 20-ml aliquots of normal saline were infused then immediately aspirated. This procedure was performed in three separate lobes. The cells were then separated from the lavage fluid by centrifugation and washed twice in RPMI-1640 (Biofluids, Inc., Rockville, MD).

To obtain purified preparations of lung and blood lymphocytes, the mononuclear cells were suspended in "culture medium" (RPMI1640 supplemented with $50 \mathrm{mM}$ glutamine, $100 \mathrm{U} / \mathrm{ml}$ penicillin, 100 $\mu \mathrm{g} / \mathrm{ml}$ streptomycin, and $10 \%$ fetal calf serum (FCS); all are from Biofluids, Inc.) and were depleted of adherent cells by adherence to plastic tissue culture dishes (100 mm diameter, Falcon 3003, BectonDickinson \& Co., Sunnyvale, CA) for $60 \mathrm{~min}$ at $37^{\circ} \mathrm{C}$, followed by passage through nylon wool columns (ABS, Inc., Buffalo, NY) (7). Nonadherent cells were eluted from the nylon wool columns at $2 \mathrm{ml} /$ min at $37^{\circ} \mathrm{C}$ using culture medium. The resulting lymphocyte populations (referred to throughout as "lymphocytes") were routinely >97\% pure as determined by morphology and nonspecific esterase staining. $>97 \%$ viable (as assessed by trypan blue exclusion), and contained $<3 \%$ B cells (as determined by direct immunofluorescence using the anti-B cell monoclonal antibody Leu 12, from Becton-Dickinson \& Co.).

Lung and blood mononuclear phagocytes were purified from the mononuclear cell populations by adherence to $10-\mathrm{cm}$ plastic dishes for $1 \mathrm{~h}$ at $37^{\circ} \mathrm{C}$ (lung) or $30 \mathrm{~min}$ at $37^{\circ} \mathrm{C}$ (blood) in culture medium, then removed using a disposable cell scraper (Costar, Cambridge, MA). The resulting mononuclear phagocyte populations were $>98 \%$ pure (lung) and $>90 \%$ pure (blood); both populations were $85 \pm 6 \%$ viable as assessed by trypan blue exclusion.

Identification of $\mathrm{NK}$ cells. The proportions of lymphocytes in lung and blood with morphologic features of large granular lymphocytes (LGL) were determined by examining methanol-fixed cytospin preparations using Giemsa stain (Manufacturing Chemists, Inc., Gibbstown, $\mathrm{NJ}$ ) that was diluted 1 in 20 in phosphate-buffered saline (PBS) for 12 min. Fixation, staining, and washing were all performed at pH 7.2.

2. All data are presented as mean $\pm \mathrm{SE}$ of the mean; comparisons between groups were performed using the two-tailed $t$ test.
LGL were enumerated using established criteria including lymphocytoid morphology, high cytoplasm nucleus ratio, and multiple cytoplasmic granules (8).

The frequency of surface antigen marker (HNK-1) antigen-bearing lung and blood lymphocytes was determined using direct immunofluorescence (9). Briefly, $10 \mu \mathrm{l}$ of fluorescein conjugated anti-Leu 7 (HNK1) monoclonal antibody suspension (Becton-Dickinson \& Co.), was added to $100 \mu \mathrm{l}$ of cell suspension $\left(10^{7} / \mathrm{ml}\right)$ and incubated at $4^{\circ} \mathrm{C}$ for $30 \mathrm{~min}$. After washing four times in cold $\left(4^{\circ} \mathrm{C}\right) \mathrm{PBS}$, the frequency of HNK-1 positive lymphocytes was determined using phase-contrast and fluorescent microscopy.

Partial purification of NK cells. NK cells were partially purified by discontinuous Percoll gradient centrifugation using LGL morphology as a criterion for purity (10). Percoll (Pharmacia Fine Chemicals, Piscataway, NJ) was made isosmotic by the addition of $10 \% \mathrm{vol} / \mathrm{vol}$ 10-fold concentrated Hanks' balanced salt solution (HBSS) (Biofluids, Inc.) and added in various proportions to culture medium (corrected to $285 \mathrm{mosmol}$ ) to produce solutions that ranged from 41.7 to $66.7 \%$ Percoll (vol/vol). The resulting seven solutions were carefully layered on top of each other in a 15-ml polystyrene tube (Falcon 2095, BectonDickinson \& Co.). Nylon-wool purified lymphocytes $\left(40 \times 10^{6} / \mathrm{ml}\right.$ in culture medium) were then layered on top of the gradient and centrifuged at $550 \mathrm{~g}$ for $30 \mathrm{~min}$ at $23^{\circ} \mathrm{C}$. Cells from the second and third interfaces were removed using a pasteur pipette, washed twice in HBSS, and depleted of high affinity sheep red blood cell (SRBC) rosette-forming cells (11). To accomplish this, $10^{6}$ lymphocytes in 2.5 $\mathrm{ml} \mathrm{RPMI}-1640$ were added to $5 \mathrm{ml}$ FCS and $5 \mathrm{ml}$ washed SRBC $\left(10^{8} /\right.$ $\mathrm{ml}$ RPMI-1640), incubated for $5 \mathrm{~min}$ at $37^{\circ} \mathrm{C}$, centrifuged at $150 \mathrm{~g}$ for $5 \mathrm{~min}$, and incubated at $29^{\circ} \mathrm{C}$ for $1 \mathrm{~h}$. The SRBC rosette-forming cells were then removed by density gradient centrifugation through lymphocyte separation medium at $400 \mathrm{~g}$ for $30 \mathrm{~min}$ at $23^{\circ} \mathrm{C}$, the cells at the interface were recovered, washed twice, and resuspended in culture medium. The preparations were comprised of $80-85 \%$ LGL as assessed by Giemsa stain and were used at a 10:1 ratio with target cells in the ${ }^{51} \mathrm{Cr}$-release assay.

Target cells. The human myeloid cell line $\mathrm{K} 562$, which was kindly provided by J. Djeu, Food and Drug Administration, Bethesda, MD, was used as the target cell except where stated otherwise. The myeloid cell line U937 and the lymphoblastoid cell lines MOLT-3 and Raji were obtained from the American Type Culture Collection, Rockville, MD, and the lymphoblastoid cell line Daudi was kindly provided by J. Wunderlich, National Cancer Institute, Bethesda, MD. All cell lines were maintained in culture medium and passaged twice weekly.

${ }^{51} \mathrm{Cr}$-Release assay. NK activity was assessed using a ${ }^{51} \mathrm{Cr}$-release assay (12). To accomplish this, target cells were centrifuged at $400 \mathrm{~g}$ for $5 \mathrm{~min}$, incubated with $\mathrm{Na}\left[{ }^{31} \mathrm{Cr}\right]$ chromate $(350 \mathrm{mCi} / \mathrm{mg} \mathrm{Cr} ; 1 \mathrm{mCi} /$ $\mathrm{ml}$; Amersham Corp., Arlington Heights, IL) for $90 \mathrm{~min}$ at $37^{\circ} \mathrm{C}$, washed twice with HBSS, incubated for $30 \mathrm{~min}$ at $37^{\circ} \mathrm{C}$ in culture medium, centrifuged again, and resuspended in culture medium at $10^{5}$ cells $/ \mathrm{ml}$. Viability at this stage was routinely $>95 \%$ as assessed by trypan blue exclusion.

Unless otherwise stated, NK activity was assessed using $2.5 \times 10^{5}$ effector cells and $5 \times 10^{3}$ target cells. The assay was performed by adding $50 \mu \mathrm{l}$ of the effector cell suspension $\left(5 \times 10^{6} / \mathrm{ml}\right.$ culture medium) to wells of a Linbro 96-well V-bottom tissue culture plate (Flow Laboratories, Inc., McLean, VA). The target cell suspension $\left(100 \mu \mathrm{l} ; 10^{5} / \mathrm{ml}\right.$ culture medium) was then added. In some assays, 50 $\mu l$ of various test preparations were added to the effector cells and control wells for $24 \mathrm{~h}$ before the addition of target cells. Assays were performed in quadruplicate. The plates were lightly centrifuged at $\mathbf{5 0}$ 
$g$ for $5 \mathrm{~min}$ and incubated for $14 \mathrm{~h}$ at $37^{\circ} \mathrm{C}$. Spontaneous target cell ${ }^{51} \mathrm{Cr}$-release (background release), which was determined by incubating targets cell in culture medium alone, was $1.4 \pm 0.2 \% / \mathrm{h}$. Maximum releasable counts were determined by incubating target cells in 1:100 Triton X-100. After incubation the plates were centrifuged at $400 \mathrm{~g}$ for $5 \mathrm{~min}$ and the supernatants harvested using a Titertek supernatant collection system (Flow Laboratories, Inc.). A cytotoxicity index was then calculated as: ([release in test wells] - [background release]) $\times 100 /([m a x i m a l$ release] - [background release]).

Single cell studies. The capacity of individual blood and lung lymphocytes to bind and lyse K562 target cells was assessed using a single-cell assay (13). To accomplish this, $10^{5}$ lymphocytes and $10^{5}$ target cells were added together to a 5-ml polypropylene tube (Falcon 2063 , Becton-Dickinson \& Co.), incubated for $5 \mathrm{~min}$ at $30^{\circ} \mathrm{C}$, and centrifuged at $250 \mathrm{~g}$ for $5 \mathrm{~min}$ at $23^{\circ} \mathrm{C}$. The supernatant was discarded and the cell pellet gently resuspended four times using a pasteur pipette. A small aliquot was then examined using a hemacytometer and the percentage of cells binding to target cells (referred to as "conjugate formation") was determined as: ([number of lymphocytes bound to target cells] $\times 100 /[$ total number of lymphocytes]). The remainder of the cell pellet was then taken up in $50 \mu \mathrm{l}$ of $2 \%$ agarose (FMC Corp., Marine Colloids Division, Rockland, ME) at $40^{\circ} \mathrm{C}$ and immediately placed on an agarose-coated glass slide. The cell-agarose suspension was then allowed to solidify on the slide at $23^{\circ} \mathrm{C}$ and the slide was placed in a sterile Coplin slide jar that contained culture medium. After incubation for $14 \mathrm{~h}$ at $37^{\circ} \mathrm{C}$ the slides were removed, stained with $2 \%$ trypan blue solution for $5 \mathrm{~min}$, rinsed, and then fixed in PBS that contained $0.3 \%$ formalin. The slide was then examined using light microscopy and the frequency of lymphocyte-bound and unbound target cells that stained with trypan blue (i.e., "dead" cells) was determined. The single cell cytotoxicity was quantified as: ([percentage of conjugates that contained dead target cells] - [percentage of spontaneous lysis]). On the average, the spontaneous lysis of target cells was $3.0 \pm 0.3 \%$

Inhibition studies. To evaluate the hypothesis that NK cell activity in the human lung is suppressed because of local inhibitory influences, alveolar macrophages and epithelial lining fluid (ELF) that were recovered from normal individuals were evaluated for their capacity to inhibit autologous blood NK cell activity. To determine if alveolar macrophages could directly inhibit NK cell activity, alveolar macrophages ( $>98 \%$ pure) were added in varying numbers to blood lymphocytes or LGLs in the ${ }^{51} \mathrm{Cr}$-release assay just before the addition of target cells. In some experiments, partially purified peripheral blood monocytes were added instead of alveolar macrophages.

To determine if alveolar macrophages could cause persistent alterations in NK cell function, alveolar macrophages $\left(10^{6}\right)$ and normal blood lymphocytes $\left(2 \times 10^{6}\right)$ or LGLs $\left(10^{6}\right)$ were co-cultured for $24 \mathrm{~h}$ at $37^{\circ} \mathrm{C}$ in 24-well plates (Falcon 3047 , Becton-Dickinson \& Co.). The lymphocytes were then depleted of contaminating macrophages by passage through nylon wool columns, washed twice in RPMI-1640, and then assayed for NK activity. Control lymphocytes were handled identically but without the addition of alveolar macrophages.

To evaluate a possible role for prostaglandins or oxygen radicals, known inhibitors of NK activity, in alveolar macrophage-mediated NK regulation, a prostaglandin synthetase inhibitor (indomethacin, Sigma Chemical Co., St. Louis, MO) or antioxidants (superoxide dismutase and catalase, Sigma Chemical Co.), respectively, were added to the alveolar macrophage preparations that were used in both the ${ }^{51} \mathrm{Cr}$-release assay and the alveolar macrophage-lymphocyte co-cultivation assay as described above. The final concentration of indomethacin $\left(10^{-5} \mathrm{M}\right)$ was sufficient to suppress the production of E-series prostaglandins by alveolar macrophages, as assessed by culturing the macrophages alone and measuring prostaglandin release into the supernatant using radioimmunoassay (14). The final concentrations of superoxide dismutase $(200 \mathrm{U} / \mathrm{ml})$ and catalase $(2,000 \mathrm{U} / \mathrm{ml})$ were sufficient to suppress all $\mathrm{O}_{2}^{-}$and $\mathrm{H}_{2} \mathrm{O}_{2}$ release by the alveolar macrophages, as assessed by culturing the macrophages alone and measuring superoxide release using a ferricytochrome $C$ reduction assay (15) and hydrogen peroxide release using a phenol red oxidation assay (16). Indomethacin and antioxidants in these concentrations did not significantly alter the NK activity of lymphocytes alone or the spontaneous lysis of target cells $(P>0.1$ for all conditions).

To determine if the noncellular constituents of ELF from normal lungs could alter NK cell activity, lung lavage fluid, which represented approximately a 1:100 dilution of ELF in the normal saline used for lavage (as determined by comparing urea concentrations in lavage fluid and blood [17]), was added in varying concentrations to the ${ }^{51} \mathrm{Cr}$ release assay before the addition of target cells. In some experiments, lavage fluid was concentrated 100-fold using a Minicon B-15 macrosolute concentrator (Amicon Corp., Danvers, MA) in order to restore the concentrations of macromolecules of $>15,000 \mathrm{~mol} w \mathrm{wt}$ to their approximate in vivo values, and then diluted one in four in the ${ }^{51} \mathrm{Cr}$-release assay. As a control, normal saline was tested in all assays on both effector and target cells. ELF did not alter spontaneous target cell lysis $(P>0.5)$. To determine if ELF could cause persistent alterations in NK cell function, normal blood lymphocytes $\left(2 \times 10^{6}\right)$ or LGLs $\left(10^{6}\right)$ were incubated for $24 \mathrm{~h}$ in a 1:2 dilution of either lavage fluid or normal saline in culture medium with the final FCS concentration adjusted to $10 \%$. The cells were then washed twice in culture medium and NK activity was determined using the ${ }^{51} \mathrm{Cr}$-release assay. In all of these studies, incubation of lymphocytes with either alveolar macrophages or ELF did not alter the numbers $(P>0.1)$ or viability $(P$ $>0.1$ ) of the effector cells.

To evaluate the effects of alveolar macrophages or ELF on the capacity of NK cells to bind and lyse target cells, a single cell assay was performed on the blood lymphocytes after 24-h co-culture with alveolar macrophages or ELF, as described above. To determine if the effects of alveolar macrophages or ELF on normal blood NK cell activity were irreversible, ${ }^{51} \mathrm{Cr}$-release assays were performed on the separated lymphocytes 24 and $48 \mathrm{~h}$ after co-culture with alveolar macrophages and ELF, and the results compared with those obtained with lymphocytes that were cultured in culture medium alone.

Augmentation studies. To determine if lung NK cell activity could be stimulated with IL-2 or gamma interferon (IFN ${ }_{\gamma}$ ), lung lymphocytes were incubated with these stimuli for $24 \mathrm{~h} 37^{\circ} \mathrm{C}$ before the addition of target cells. The source of IL-2 was supernatant from the Gibbon T cell line MLA 144, which produces IL-2 constitutively (18); this preparation will be referred to as "IL-2." In some experiments, IL-2 was purified from these supernatants using reverse-phase high pressure liquid chromatography; this preparation will be referred to as "highly purified IL-2" (19) (both preparations were kindly supplied by J. Ortaldo, Frederick Cancer Research Facility, Frederick, MD). The supernatants were free of detectable interferon, as determined by assay using vesicular stomatitis virus-induced human WISH cell lysis, and contained no lectin. The amount of IL-2 that was used in the assays $(150 \mathrm{U} / \mathrm{ml})$ was within the range of the amount released in $24 \mathrm{~h}$ by $10^{6}$ lung $\mathrm{T}$ cells of patients with active sarcoidosis (5).

To demonstrate that the stimulating agent in the MLA 144 supernatants was IL-2, two additional studies were performed. First, cells of the IL-2-dependent line CT6 were washed twice, incubated in 
serum-free conditions for $4 \mathrm{~h}$, and then incubated with the MLA 144 supernatant at $10^{7}$ cells $/ \mathrm{ml}$ for $2 \mathrm{~h}$ at $4^{\circ} \mathrm{C}$ to adsorb any IL-2 from the supernatants. The CT 6 cells were then removed by centrifugation and filtration through a 0.22- $\mu \mathrm{m}$ millex low-binding filter (Millipore Corp., Bedford, MA). Control supernatants were treated identically, except for the addition of CT6 cells. This procedure resulted in complete depletion of all IL-2 activity from the preparation as tested by proliferation of the IL-2-dependent CT6 cell line, while IL-2 activity persisted in the control supernatant. These supernatants were then tested for their capacity to augment lung NK cell activity. Second, the monoclonal antibody anti-Tac (kindly supplied by T. A. Waldmann, $\mathrm{NCI}$, Bethesda, MD) was used to block IL-2 receptor function (20). To accomplish this, $10 \mu \mathrm{l}$ of a $100-\mu \mathrm{g} / \mathrm{ml}$ suspension of the antibody was added to the assay before the addition of IL-2. Identical amounts of a control antibody of the same class were added to control wells. Neither the IL-2 preparations nor the antibody altered spontaneous target cell lysis $(P>0.2)$. Partially purified $\mathrm{IFN}_{\gamma}$ (Meloy Labs, Springfield, VA) was diluted in RPMI-1640 and used at $250 \mathrm{U} / \mathrm{ml}$. This preparation was free of IL-2, as tested by proliferation of the IL2-dependent CT6 cell line.

Evaluation of lung NK activity in patients with sarcoidosis. To determine if lung NK cell activity was enhanced in a milieu of spontaneous IL-2 release, lymphocytes from patients with active sarcoidosis, which is a disorder associated with the spontaneous release of large amounts of IL-2 by lung lymphocytes, (5) were evaluated for NK activity. As a control, blood lymphocytes from the same patients were evaluated as were the lung and blood lymphocytes from patients with inactive sarcoid. Sarcoidosis patients $(n=24$, age $38 \pm 2 \mathrm{yr} ; 7$ males, 17 females) were diagnosed using previously described criteria including lung and/or intrathoracic lymph node biopsy (21). None of the patients was receiving treatment at the time of the study. On the average, lung function testing (expressed as percentage predicted) of these patients included: vital capacity (VC), $79.0 \pm 3.5$; total lung capacity, 79.0 \pm 3.6 ; diffusing capacity (single breath $\mathrm{CO}$, corrected for alveolar volume and hemoglobin), $73.7 \pm 5.2$ and $F E V_{1} / \mathrm{VC}$ ratio, 103.1 \pm 2.8 . Patients were classified as having active disease (high intensity alveolitis) or inactive disease (low intensity alveolitis) using lavage $T$ lymphocyte and gallium-67 scan criteria, as previously described (22).

The lung lymphocytes from the sarcoidosis patients were evaluated in two ways. First, the lung lymphocytes from all sarcoid patients were evaluated for spontaneous NK activity. Second, lung lymphocytes from patients with low intensity alveolitis were incubated with IL-2 or $\mathrm{IFN}_{\gamma}$ (as described above) to determine if NK cell activity could be enhanced by these mediators. All studies with lymphocytes of sarcoidosis patients were performed as described above for lymphocytes from normal individuals.

\section{Results}

Normal lung NK cell activity. NK cell activity of normal peripheral blood lymphocytes was readily detected at all effector to target ratios tested (Fig. $1 \mathrm{~A}$ ). In marked contrast, at the same effector to target ratios, NK cell activity of normal lung lymphocytes was barely detectable. At an effector target ratio of 50:1, blood NK cell activity was $\sim 25$-fold that of lung lymphocytes $(P<0.001$ compared with blood). This marked difference of NK cell activity between blood and lung was not target specific; with the other NK-sensitive target cells tested,
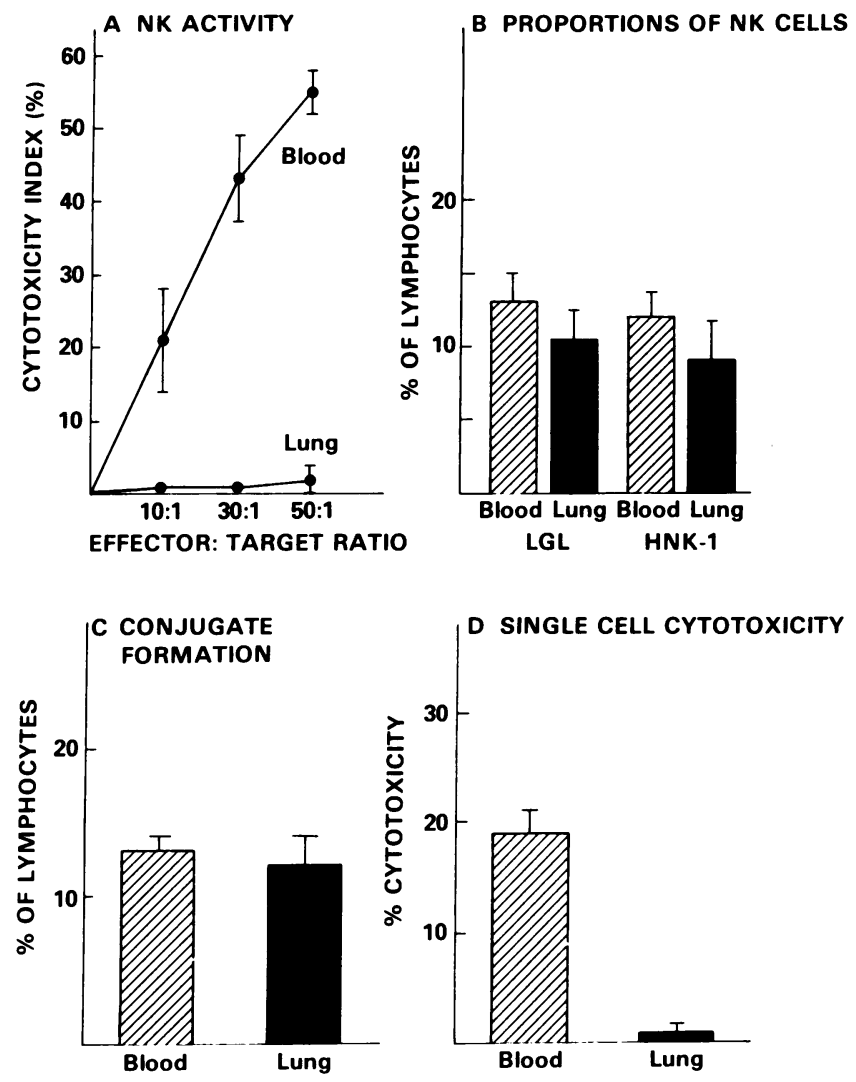

Figure 1. Comparison of normal blood and lung NK cell activity and numbers. Equal numbers of lymphocytes from blood and lung were tested in all assays. $(A)$ NK cell activity against K562 target cells. Data is presented as cytotoxicity index for increasing effector to target cell ratios; $5 \times 10^{3}$ target cells were used in all assays $(n=12$ for both blood and lung). (B) Proportions of lymphocytes with NK cell markers in blood and lung. Shown is the proportion of LGL and the proportion of cells with the cell surface antigen HNK-1 detected by the monoclonal antibody Leu 7 ( $n=6$ for both blood and lung). (C) Ability of blood and lung lymphocytes to bind to NK-sensitive targets (K562). Conjugate formation is expressed as the percentage of lymphocytes that bound to the target cells $(n=6$ for both blood and lung). (D) Ability of conjugate-forming lung and blood lymphocytes to lyse the target cells (K562). Cytotoxicity is expressed as percentage of conjugates that contained dead target cells - percentage of spontaneous target cell death ( $n=6$ for both blood and lung).

lung NK activity was similarly reduced compared with blood (U937, $2.7 \pm 2.6 \%$ vs. $56.2 \pm 5.9 \%$; MOLT $-3,0 \%$ vs. $50.9 \pm 5.0 \%$; and Daudi, $0 \%$ vs. $62.7 \pm 3.4 \% ; P<0.01$, all comparisons; lung vs. blood, $n=4$ for each target cell). Lung lymphocytes also failed to lyse the relatively NK-insensitive target Raji (lung 0\% vs. blood, $29.6 \pm 7.2 \%, n=4$ ).

Frequency of NK effector cells in the lung. Although there are no definitive morphologic or cell surface antigenic markers specific for NK cells, it is recognized that LGL morphology and the HNK-1 surface antigen are characteristics of NK cells. 
In this context, it was clear that NK cells were present in the normal lung and that, as a proportion of lymphocytes, the percentages of NK cells in lung and blood were similar $(P$ $>0.5$, all comparisons, Fig. $1 B$ ).

Single cell studies of lung lymphocyte killing of K562 cells. The percentage of lung lymphocytes that was able to recognize and bind NK-sensitive targets was similar to that of blood ( $P$ $>0.2$, Fig. $1 C$ ). However, while $\sim 20 \%$ of normal blood lymphocytes that bound to K562 target cells caused lysis of these cells, under identical conditions $<1 \%$ of the lung lymphocytes binding to K562 cells lysed the target $(P<0.001$, Fig. $1 D$ ). Thus, the lack of functional activity of lung NK cells appears to be related to failure of these cells to lyse the target after binding.

Suppression of NK cell activity by components of the lower respiratory tract. The impotence of lung NK cells appeared to be related, at least in part, to inhibitory influences in the local milieu of the lower respiratory tract. In this regard, NK activity of normal blood lymphocytes was suppressed by normal alveolar macrophages and the degree of suppression increased with increasing alveolar macrophage to lymphocyte ratios (Fig. $2 \mathrm{~A}$ ). Both indomethacin and antioxidants failed to prevent alveolar macrophage-mediated inhibition, which suggested that prostaglandins and oxygen radicals were not major mediators of this effect (Table I). Moreover, the suppressive effect of normal alveolar macrophages on NK activity persisted despite removal of the macrophages from the NK cells after $24 \mathrm{~h}$ of co-cultivation (Table I). Separate experiments using unadhered lung mononuclear phagocytes demonstrated that the adherence step itself did not alter the capacity of mononuclear phagocytes to affect NK cell function $(P>0.5, n=4)$.

Purified blood monocytes also inhibited NK cell activity. At a 1:1 monocyte to lymphocyte ratio, the degree of inhibition was $20 \pm 2 \%(P<0.05$, compared with medium alone; $n=6)$. Compared with the $62 \pm 5 \%$ inhibition expressed by alveolar macrophages at the same $(1: 1)$ ratio to lymphocytes, blood monocytes were significantly less inhibitory $(P<0.05$, compared with alveolar macrophages).

ELF also exerted a profound inhibitory effect on normal NK cell function (Fig. $2 B$ ), and this inhibitory effect persisted even after removal of the ELF after $24 \mathrm{~h}$ of co-cultivation (Table I). At a 25-fold concentration of lavage fluid (representing approximately a 1:4 dilution of ELF), the components in ELF were able to virtually abolish the NK activity of normal blood lymphocytes (Fig. 2 B). A 1:4 dilution of autologous serum did not inhibit blood NK cell activity $(P>0.5)$.

After incubation of blood lymphocytes with alveolar macrophages or ELF for $24 \mathrm{~h}$, their capacity to bind K562 cells was unaltered (Fig. $2 C, P>0.2$ ). However, under the same conditions, a dramatic reduction was observed in the capacity of conjugate-forming lymphocytes to kill the target cells $(P$ $<0.01$ for both alveolar macrophages and ELF; Fig. $2 \mathrm{D}$ ). Normal alveolar macrophages alone demonstrated negligible target cell cytotoxicity or binding ( $<1 \%$ for both). Thus, the
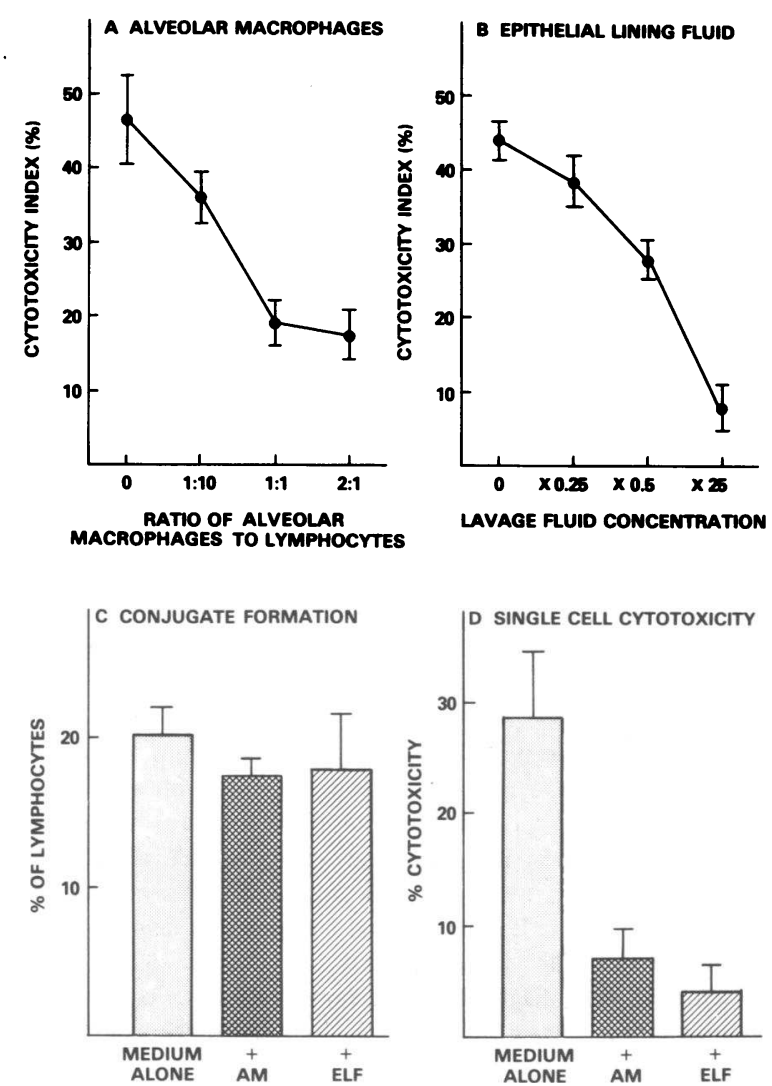

Figure 2. Suppression of NK activity by components of the normal lower respiratory tract ( $n=6$ for all experiments). $(A)$ Suppression of NK activity of normal blood lymphocytes by normal alveolar macrophages. Alveolar macrophages were added to the ${ }^{51} \mathrm{Cr}$-release assay at various macrophage to lymphocytes ratios. (B) Suppression of NK activity of normal blood lymphocytes by normal lung ELF. As recovered, ELF is diluted by the saline used for lavage and normally represents $\sim 1 \%$ of the total recovered fluid. $\times 0.25$, lavage fluid diluted $1: 4 ; \times 0.5$, lavage fluid diluted $1: 2 ; \times 25$, lavage fluid concentrated 25 -fold. In terms of actual ELF, $\times 0.25$ is approximately a 400-fold dilution, $\times 0.5$ a 200 -fold dilution, and $\times 25$ a four-fold dilution. $(C)$ Effects of co-culture of blood lymphocytes with alveolar macrophages or ELF on the ability of these lymphocytes to form conjugates with K562 target cells. (D) Effects of co-culture of blood lymphocytes with alveolar macrophages or ELF on the capacity of target-bound lymphocytes to lyse their target cells in a single cell assay in agarose. AM, alveolar macrophages.

mechanism of the alveolar macrophage and ELF suppression of NK activity was related to reduction of the ability of the NK cells to lyse their targets after they had bound to the targets. Importantly, inhibition of blood NK cell activity by alveolar macrophages and ELF was not irreversible. After their removal from the alveolar macrophages or ELF, these cells completely recovered their NK activity within 24 (ELF) or 48 h (alveolar macrophages). 
Table I. Evaluation of Alveolar Macrophage and ELF-mediated Suppression of NK Activity ( $n=6$ for All Conditions)

\begin{tabular}{|c|c|}
\hline Condition & $\begin{array}{l}\text { NK activity } \\
\text { (cytotoxicity } \\
\text { index, \%) }\end{array}$ \\
\hline Lymphocytes* alone & $50.6 \pm 13.5$ \\
\hline + Alveolar macrophages & $31.6 \pm 10.6 \S$ \\
\hline+ Alveolar macrophages $\ddagger$ indomethacin $\left(10^{-5} \mathrm{M}\right)$ & $31.5 \pm 15.0^{11}$ \\
\hline + Alveolar macrophages + antioxidants & $40.5 \pm 14.9^{\prime \prime}$ \\
\hline Lymphocytes* cultured for $24 \mathrm{~h}$ alone & $67.8 \pm 6.4$ \\
\hline+ Alveolar macrophages** & $48.5 \pm 5.8 \S$ \\
\hline + Alveolar macrophages + indomethacin $\left(10^{-5} \mathrm{M}\right)$ & $53.4 \pm 5.4^{\| \prime}$ \\
\hline + Alveolar macrophages + antioxidants & $46.0 \pm 6.6^{\prime \prime}$ \\
\hline 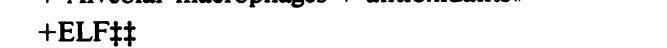 & $44.5 \pm 5.1 \S$ \\
\hline
\end{tabular}

* Blood lymphocytes isolated by depletion of adherent cells using plastic and nylon wool.

‡ Normal alveolar macrophages added to lymphocytes in the cytotoxicity assay; alveolar macrophages to lymphocyte ratio $1: 1$.

$\S P<0.001$, compared with lymphocytes alone.

" $P>0.1$, compared with lymphocytes plus alveolar macrophages.

T Superoxide dismutase $(200 \mathrm{U} / \mathrm{ml})$ plus catalase $(2,000 \mathrm{U} / \mathrm{ml})$.

** Normal alveolar macrophages cultured with lymphocytes for $24 \mathrm{~h}$

then removed by passage through nylon wool (AM to lymphocyte ratio $1: 2$ ).

$\ddagger \ddagger$ Normal blood lymphocytes cultured in ELF for $24 \mathrm{~h}$, washed twice, then assayed for NK activity.

The NK activity of LGL purified from blood was similarly inhibited by both alveolar macrophages $(48 \pm 21 \%$ inhibition) and ELF (32 $\pm 9 \%$ inhibition) $(P<0.05$, all comparisons, $n$ $=5$ ). As was observed with the unfractionated lymphocytes, this effect persisted after removal of the alveolar macrophages after 24 h co-cultivation (38 $\pm 13 \%$ inhibition, $P<0.05$ ) or ELF after $24 \mathrm{~h}$ co-cultivation ( $25 \pm 9 \%$ inhibition, $P<0.05, n=5)$.

Augmentation of normal lung NK cell activity. Although NK cell activity is very low in the normal lung, this activity could be augmented in vitro. First, normal lung lymphocytes that were incubated in medium alone for $24 \mathrm{~h}$ demonstrated a significant increase in NK activity $(P<0.01)$ (Fig. 3). This increase was also observed when the cells were cultured in the presence of autologous serum rather than FCS. Furthermore, addition of IL-2 to these cultures of lymphocytes resulted in further augmentation of NK activity, compared with lymphocytes that were cultured alone $(P<0.05$; two-tailed paired $t$ test). In contrast, no augmentation of lung NK cell activity was seen after incubation with $\operatorname{IFN}_{\gamma}(P>0.2$, compared with lymphocytes cultured alone). Both IL- 2 and IFN $\mathrm{I}_{\gamma}$ augmented blood lymphocyte NK activity under the same conditions $(P$ $<0.05$, both comparisons to blood lymphocytes cultured in medium alone).

NK cell activity in the sarcoid lung. Lung lymphocytes from sarcoidosis patients with low intensity alveolitis expressed

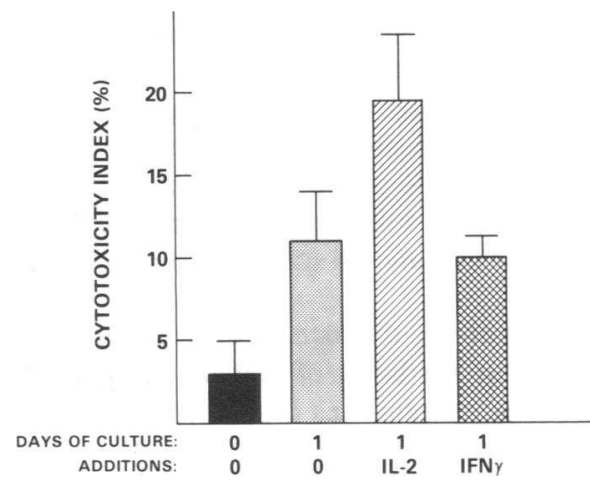

Figure 3. Expression of lung NK activity against K562 targets when the "impotent" NK cells are removed from the lung and maintained in culture for $1 \mathrm{~d}$. Lung lymphocytes from normal individuals were evaluated for NK activity immediately or after $1 \mathrm{~d}$ in culture with medium alone or in the presence of IL-2 or $\operatorname{IFN}_{\gamma}(n=8)$.

a low level of NK activity, similar to that of normal lungs ( $P$ $>0.5$, Fig. $4 A$ ). In marked contrast, lymphocytes from the lungs of sarcoidosis patients with high intensity alveolitis, a condition known to be associated with the spontaneous release of IL-2 by lung $T$ cells, demonstrated significantly higher NK activity compared with lung lymphocytes from normal individuals and sarcoidosis patients with low intensity alveolitis $(P$ $<0.02$, both comparisons). Furthermore, this increase in lung NK cell activity was observed with each of three other NKsensitive targets that were evaluated (U937, 20.0 $44.6 \%$; MOLT3, 17.8 $\pm 5.4 \%$; Daudi, $18.7 \pm 13.1 \%$; all $P<0.02$ compared with normal, $n=6$ ), but not the relatively NK-insensitive Raji target $(0.8 \pm 0.7 \%, P>0.2)$. However, while lung lymphocytes

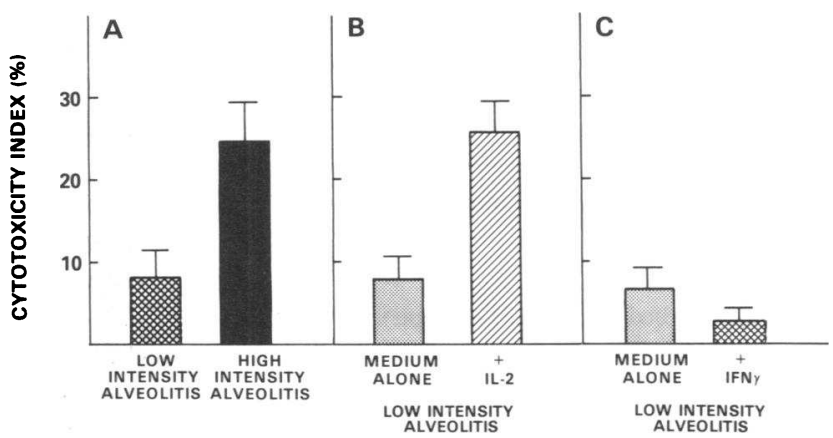

Figure 4. Lung NK cell activity of patients with pulmonary sarcoidosis. $(A)$ Lung NK cell activity of patients with inactive disease (low intensity alveolitis $[n=11]$ ) and active disease (high intensity alveolitis [ $n=13])$. (B) NK cell activity of lung lymphocytes of patients with inactive sarcoidosis incubated in vitro for $24 \mathrm{~h}$ in medium alone or in medium containing IL-2 $(n=7)$. (C) NK cell activity of lung lymphocytes incubated in vitro for $24 \mathrm{~h}$ in medium alone or in medium containing $\operatorname{IFN}_{\gamma}(n=6)$. In all studies, NK cell activity was measured against K562 targets and the same numbers of lung lymphocytes were used in all assays. 
of patients with high intensity alveolitis exhibited markedly higher NK cell activity, blood lymphocytes of these patients had similar NK cell activity to blood lymphocytes of patients with low intensity alveolitis and normal individuals $(P>0.1$, all comparisons). Active lung NK cells from patients with high intensity sarcoidosis were also inhibited by normal alveolar macrophages and ELF ( $39 \pm 19$ and $84 \pm 5 \%$ inhibition, respectively).

One possible explanation for the high NK cell activity (on a per lymphocyte basis) in the lungs of patients with active sarcoidosis is that the lung lymphocytes had been modified in vivo by a $T$ cell mediator such as IL-2, i.e., functionally inactive lung NK cells in the presence of IL-2 in the local milieu become active. In this context, when lung lymphocytes that expressed low NK activity from sarcoid patients with low intensity alveolitis were incubated for $24 \mathrm{~h}$ in the presence of IL-2, their NK activity was augmented significantly ( $P$ $<0.001$, Fig. $4 B$ ) to a level similar to that seen in sarcoidosis patients with high intensity alveolitis $(P>0.5)$. However, no augmentation was seen after incubation of lung lymphocytes

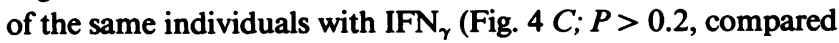
with lymphocytes alone).

Several lines of evidence suggested that it was IL-2 and not other components in the MLA 144 cell line IL-2 preparation that caused the in vitro augmentation of the lung lymphocyte NK activity (Table II). First, IL-2 that was purified from supernatants of this cell line produced identical results. Second, depletion of IL-2 from the cell line supernatant by adsorption to the IL-2-dependent cell line CT6 completely removed the NK-augmenting effect of the preparation. Third, blockade of

Table II. Evidence that IL-2 Is Responsible for the In Vitro Augmentation of Lung NK Cell Activity ( $n=6$ for All Experiments)

\begin{tabular}{ll}
\hline Condition & $\begin{array}{l}\text { NK activity } \\
\text { (cytotoxicity } \\
\text { index, \%) }\end{array}$ \\
\hline Lung lymphocytes cultured alone (for $24 \mathrm{~h})^{*}$ & $13.8 \pm 2.7$ \\
$\quad$ +IL-2 & $32.0 \pm 4.5 \S$ \\
+Highly purified IL-2" & $28.1 \pm 7.4 \S$ \\
+IL-2 adsorbed with the IL-2-dependent CT6 & \\
$\quad$ cell line & $12.8 \pm 2.8 \pi$ \\
+IL-2 + anti-Tac** & $14.1 \pm 4.3 \pi$ \\
+IL-2 + control antibody $¥ \ddagger$ & $30.4 \pm 5.9 \S$
\end{tabular}

* Lymphocytes isolated from lung mononuclear cell populations by depletion of adherent cells using plastic and nylon wool.

₹ "IL-2" equals supernatant of MLA 144 cell line; see Methods. $\S P<0.05$, compared with lymphocytes alone.

"IL-2 purified from supernatant of MLA 144 cell line using reversephase high performance liquid chromatography (20).

II $P>0.2$, compared with lymphocytes alone.

** Anti-Tac added to lymphocytes before the addition of IL-2. ¥ Control antibody (RPC5) added as in ".
IL-2 receptors using the monoclonal antibody anti-Tac likewise abrogated the NK-augmenting effect.

\section{Discussion}

In order to defend an organ against malignant or other abnormal cells, NK cells must not only be present locally but they must also be active. The present study demonstrates a striking compartmentalization between NK cell activity in lung and blood, such that the normal lung is virtually devoid of NK cell activity. Several lines of evidence suggest that this apparent lack of lung NK cell activity occurs even though lymphocytes with the characteristics of NK cells are present in the population of lung lymphocytes. First, the normal lung contains significant numbers of LGLs, which are cells that contain the subset of lymphocytes that mediate NK cell activity (8). Second, the lung contains significant numbers of lymphocytes that express the HNK-1 antigen, which is a property also associated with cells that, at least in blood, express NK activity (9). Third, a significant number of lung lymphocytes spontaneously bind to K562 cells, which is a sensitive though not specific feature of NK cells (23-26). Thus, it appears that while NK cells are present in the normal lung, these cells are functionally impotent.

Suppression of NK cell activity by components of the lower respiratory tract. One possible explanation for the apparent impotence of NK cells in the normal lung is that there are local regulatory influences suppressing NK cell activity within the lower respiratory tract. The present study demonstrates that normal human alveolar macrophages and constituents of ELF of the normal human lower respiratory tract can markedly inhibit NK cell activity of normal blood. These findings are consistent with the observations that activated blood monocytes (27) and alveolar macrophages obtained from patients with lung disease (28) also suppress NK cell function. Both alveolar macrophages and ELF inhibit the capacity of blood lymphocytes to lyse target cells, rather than their capacity to bind to these targets. This defect in the lytic step is identical with that seen in NK cells from normal lung, which suggests that this mechanism of suppression may be operative in vivo. The inhibitory effect of normal alveolar macrophages and ELF on NK cell activity appears to be a direct effect on the NK effector cells rather than an indirect effect through other lymphocytes, since similar results were obtained when purified LGL populations were studied rather than nylon wool-purified blood lymphocytes.

It is known that E series prostaglandins (29) and oxygen radicals (27), known products of human alveolar macrophages (14, 15), can suppress NK cell activity. However, neither indomethacin nor antioxidants prevented the alveolar macrophage-mediated suppression in these experiments, which suggests that other macrophage products play a role in suppressing lung NK cell activity. Although the mechanisms by which ELF suppress NK activity are not known, cytophilic IgG (30) 
and $\alpha 1$-antitrypsin (31), known constituents of normal ELF (6, 32), can suppress NK activity.

Although all of the lung components that were used in the present study were obtained from the epithelial surface of the lower respiratory tract, it is likely that similar inhibitory influences are present throughout the alveolar walls. For example, lymphocytes that were obtained by teasing apart rat lungs (33) and human pneumonectomy specimens from patients with malignancy (34) also demonstrate little NK cell activity. Low NK cell activity is not necessarily restricted to the lung; however, it has been shown that the lymphocyte populations of human tonsils, lymph nodes, and spleen have much less NK cell activity than blood lymphocytes (35), which is consistent with the concept that the activity of NK cells in the blood is not an accurate reflection of NK cell activity in specific organs.

The mechanism that underlies the diminished NK cell activity in these organs is not known, but it may involve local suppressive influences, as in the lung, and/or the absence in these organs of mediators that are necessary for the maintenance of NK cell function. In this context it has been shown that blood NK cells do not maintain their activity when cultured in the absence of IL-2, but do so if IL-2 is added to the cultures (36).

Augmentation of lung NK cell activity. While lung NK cell activity is normally suppressed, it is clear that this can be overcome in vitro, and, in certain circumstances, in vivo. First, when blood NK cells are suppressed by alveolar macrophages or ELF in vitro, this suppression is lost within 24-48 h after their removal from the alveolar macrophages or ELF. Second, lung lymphocytes express significant NK cell activity after 24 $h$ culture in medium alone. Third, exposure of normal lung lymphocytes to IL-2 in vitro uncovers lung NK cell activity. Fourth, in active pulmonary sarcoidosis, a condition in which lung $\mathrm{T}$ lymphocytes are spontaneously releasing IL-2, lung NK cell activity is markedly increased over that seen in the lungs of normal individuals. Fifth, the low NK activity of lung lymphocytes from patients with inactive sarcoidosis can be augmented by culturing these cells with IL-2. Sixth, the fact that NK activity is present in the lungs when IL-2 is present is consistent with the demonstration of in vivo enhancement of NK cell activity after the administration of IL-2 to rats (37).

It is possible that the enhanced lung NK cell activity in sarcoidosis patients is due to several mechanisms, which include a reduction in suppressive influences as well as exposure of lung NK cells to mediators in addition to IL-2. In this context, it is known that lung mononuclear cells in this disease also spontaneously release IFN $_{\gamma}$ (Robinson, B., R. Crystal, submitted for publication). Furthermore, the increase in lung NK cell activity after incubation for $24 \mathrm{~h}$ in IL-2 was greater in the inactive sarcoidosis patients than in the normals, which suggests a qualitative or quantitative difference in the resting cell population that rendered these cells more responsive to IL-2 modulation; i.e., it is possible that prior exposure of these cells to IL-2 and/or other mediators when the disease was "active" primed them to be responsive to IL-2. In this regard, it has been recently shown that HNK-1 positive cells must be primed by an initial signal to express IL-2 receptors before being responsive to IL-2 (38), and that mediators such as IFN ${ }_{\gamma}$ can contribute to the induction of IL-2 receptor expression on blood lymphocytes (39).

Interestingly, IFN $\mathrm{I}_{\gamma}$, at a dose that augmented blood NK cell activity did not augment lung NK cell activity of normals or patients with inactive sarcoidosis. These observations are consistent with observations that: (a) IL-2, but not interferon, overcomes the deficient blood NK cell activity of patients with the acquired immune deficiency syndrome (40), and (b) blood NK cell activity is profoundly depressed in patients with systemic lupus erythematosis (41), which is a disease associated with defective IL-2 production (42) yet high serum levels of interferon (43).

\section{Acknowledgments}

Dr. Robinson was partially supported by a fellowship in Applied Health Sciences, National Health and Medical Research Council of Australia.

\section{References}

1. Herberman, R. B. 1981. Natural killer (NK) cells and their possible roles in resistance against disease. Clin. Immunol. Rev. 1:165 .

2. Roder, J. C., and H. F. Pross. 1982. Biology of the human natural killer cell. J. Clin. Immunol. 2:249-263.

3. Hunninghake, G. W., and R. G. Crystal. 1981. Pulmonary sarcoidosis: a disorder mediated by excess helper T-lymphocyte activity at sites of disease activity. N. Engl. J. Med. 305:429-434.

4. Henney, C. S., K. Kuribayashi, D. E. Kern, and S. Gillis. 1981. Interleukin-2 augments natural killer cell activity. Nature (Lond.). 291:335-338.

5. Pinkston, P., P. B. Bitterman, and R. G. Crystal. 1983. Spontaneous release of interleukin-2 by lung $T$-lymphocytes in active pulmonary sarcoidosis. N. Engl. J. Med. 308:793-850.

6. Hunninghake, G. W., J. E. Gadek, O. Kawanami, V. J. Ferrans, and R. G. Crystal. 1979. Inflammatory and immune processes in the human lung in health and disease: evaluation by bronchoalveolar lavage. Am. J. Pathol. 97:149-206.

7. Henry, C. 1980. Nylon wool. In Selected Methods in Cellular Immunology. B. B. Mishel and S. M. Shigi, editors. W. H. Freeman, San Francisco. 182-185.

8. Timonen, T., J. R. Ortaldo, and R. B. Herberman. 1981. Characteristics of human large granular lymphocytes and relationship to natural killer and K-cells. J. Exp. Med. 153:569-582.

9. Abo, T., and C. M. Balch. 1981. A differentiation antigen of human NK and $\mathrm{K}$ cells identified by a monoclonal antibody (HNK1). J. Immunol. 127:1024-1029.

10. Timonen, T., and E. Saksela. 1980. Isolation of human NK cells by density gradient centrifugation. J. Immunol. Methods. 36:285291.

11. West, W. H., G. B. Cannon, H. D. Kay, G. D. Bonnard, and R. B. Herberman. 1977. Natural cytotoxic reactivity of human lym- 
phocytes against a myeloid cell line: characteristics of effector cells. $J$. Immunol. 118:355-359.

12. Grabstein, K. 1980. Cell-mediated cytolytic responses. In Selected Methods in Cellular Immunology. B. B. Mishel and S. M. Shigi, editors. W. H. Freeman, San Francisco. 128-136.

13. Bonavida, B., T. P. Bradley, and E. A. Grimm. 1983. Frequency determination of killer cells by a single-cell cytotoxicity assay. In Methods in Enzymology, Vol. 93. J. J. Langone and H. van Vanakis, editors. Academic Press, Inc., New York. 270-279.

14. Ozaki, T., S. Rennard, and R. G. Crystal. 1983. Production of prostaglandins by guinea pig and human alveolar macrophages. $\mathrm{Am}$. Rev. Respir. Dis. 127(s):275. (Abstr.)

15. Hoidal, J. R., R. B. Fox, P. A. Le Marbe, R. Rem, and J. E. Repine. 1980. Altered oxidative metabolic responses in vitro of alveolar macrophages from asymptomatic cigarette smokers. Am. Rev. Respir. Dis. 123:85-89.

16. Pick, E., and Y. Keisari. 1980. A simple colorimetric method for the measurement of hydrogen peroxide produced by cells in culture. J. Immunol. Methods. 38:161-170.

17. Buchalter, S., S. Rennard, J. Fulmer, G. Basset, and R. Crystal. 1984. Evidence for alveolar edema and capillary leak in the lower respiratory tract of patients with sarcoidosis and idiopathic pulmonary fibrosis. Am. Rev. Respir. Dis. 129(Pt. 2):A64. (Abstr.)

18. Rabin, H., R. F. Hopkins III, F. W. Ruscett, R. H. Nubauer, R. L. Brown, and T. G. Kawanami. 1956. Spontaneous release of a factor with properties of $\mathrm{T}$-cell growth factor from a continuous line of primate tumor T-cells. J. Immunol. 127:1852-1856.

19. Henderson, L. E., J. F. Hewetson, R. F. Hopkins III, R. C. Sowder, R. H. Newbauer, and H. Rabin. 1983. A rapid large scale purification procedure for Gibbon interleukin-2. J. Immunol. 810815.

20. Depper, J. M., W. J. Leonard, R. J. Robb, T. A. Waldmann, and W. C. Greene. 1983. Blockade of the interleukin-2 receptor by anti-Tac antibody: inhibition of human lymphocyte activation. J. Clin. Invest. 131:690-696.

21. Crystal, R. G., W. C. Roberts, G. W. Hunninghake, J. E. Gadek, J. D. Fulmer, and B. R. Line. 1981. Pulmonary sarcoidosis: a disease characterized and perpetuated by activated lung T-lymphocytes. Ann. Intern. Med. 94:73-94.

22. Keogh, B. A., G. W. Hunninghake, B. R. Line, and R. G. Crystal. 1983. The alveolitis of pulmonary sarcoidosis: evaluation of natural history and alveolitis dependent changes in lung function. Am. Rev. Respir. Dis. 128:256-265.

23. Ullberg, M., and M. Jondal. 1981. Recycling and target binding capacity of human natural killer cells. J. Exp. Med. 153:615-628.

24. Hiserodt, J. C., L. J. Britvan, and S. R. Targan. Differential effects of various pharmacologic agents on the cytotoxic reaction mechanism of the human killer lymphocyte: further resolution of programming for lysis and kill into discrete stages. J. Immunol. 129:2266-2270.

25. Roger, J. C., L. Ahrland-Richter, and M. Jondal. 1979. Targeteffector interaction in the human and murine natural killer system. $J$. Exp. Med. 150:471-481.

26. Rubin, P., H. F. Pross, and J. C. Roder. 1982. Studies of human natural killer cells. II. Analysis at the single cell level. $J$. Immunol. 128:2553-2558.

27. Seaman, W. E., T. D. Gindhart, M. A. Blackman, B. Dalal, N. Tolol, and Z. Werb. 1982. Suppression of natural killing in vitro by monocytes and polymorphonuclear leukocytes. Requirement for reactive metabolites of oxygen. J. Clin. Invest. 69:876-888.

28. Bordignon, C., F. Villa, P. Allavera, M. Introna, A. Biondi, R. Avallone, and A. Mantovani. 1982. Inhibition of natural killer activity by human bronchoalveolar macrophages. J. Immunol. 129:587-591.

29. Koren, H. S., S. J. Anderson, D. G. Fischer, C. S. Copeland, and P. J. Jensen. 1981. Regulation of human natural killing. I. Role of monocytes, interferon and prostaglandins. J. Immunol. 127:20072013.

30. Sulica, A., M. Gherman, C. Galatiuc, M. Manciulea, and R. B. Herberman. 1982. Inhibition of human natural killer cell activity by cytophilic immunoglobulin G. J. Immunol. 128:1031-1036.

31. Hudig, D., T. Haverty, C. Fulcher, D. Redelman, and J. Mendelsohn. 1981. Inhibition of human natural cytotoxicity by macromolecular antiproteases. J. Immunol. 126:1569-1574.

32. Gadek, J. E., G. A. Fells, R. L. Zimmerman, S. I. Rennard, and R. G. Crystal. 1981. Antielastases of the human alveolar structures. J. Clin. Invest. 68:889-898.

33. Reynolds, C. W., T. Timonen, and R. B. Herberman. 1981. Natural killer (NK) cell activity in the rat. Isolation and characterization of the effector cells. J. Immunol. 127:282-287.

34. Bordignon, C., F. Villa, A. Vecchi, R. Giavazzi, M. Introna, R. Avallone, and A. Mantovani. 1982. Natural cytotoxic activity in human lungs. Clin. Exp. Immunol. 47:437-444.

35. Si, L., and T. L. Whiteside. 1983. Tissue distribution of human NK cells studied with anti Leu-7 monoclonal antibody. J. Immunol. 130:2149-2155.

36. Domzig, W., B. M. Stadler, and R. B. Herberman. 1983. Interleukin-2 dependence of human natural killer (NK) cell activity. J. Immunol. 130:1970-1973.

37. Hefeneider, S. H., P. J. Conlon, C. S. Henney, and S. Gillis. 1983. In vivo interleukin-2 administration augments the generation of alloreactive cytolytic T-lymphocytes and resident natural killer cells. J. Immunol. 130:222-227.

38. Abo, T., C. A. Miller, C. M. Balch, and M. D. Cooper. 1983. Interleukin-2 receptor expression by activated $\mathrm{HNK}-1^{+}$granular lymphocytes: a requirement for their proliferation. J. Immunol. 131:18221826.

39. Johnson, H. M., and W. L. Farran. 1983. The role of gamma interferon-like lymphokine in the activation of T-cells for expression of interleukin-2 receptors. Cell Immunol. 75:154-159.

40. Rook, A. H., H. Masur, H. C. Lane, W. Frederick, T. Kasahara, A. M. Macher, J. Djeu, J. F. Manischewitz, L. Jackson, A. Fauci, and G. V. Quinnan, Jr. 1983. Interleukin-2 enhances the depressed natural killer and cytomegalovirus-specific cytotoxic activities of lymphocytes from patients with the acquired immune deficiency syndrome. J. Clin. Invest. 72:398-403.

41. Neighbour, P. A., A. I. Grayzel, and A. E. Miller. 1982. Endogenous and interferon-augmented natural killer cell activity of peripheral blood mononuclear cells in vitro. Studies of patients with multiple sclerosis, systemic lupus erythematosis or rheumatoid arthritis. Clin. Exp. Immunol. 49:11-21.

42. Linker-Israeli, M., A. C. Bakke, R. C. Kitridou, S. Gendler, S. Gillis, and D. A. Horwitz. 1983. Defective production of interleukin1 and interleukin-2 in patients with systemic lupus erythematosis (SLE). J. Immunol. 130:2651-2655.

43. Hooks, J. J., H. M. Moutsopolous, S. A. Geis, N. I. Stahl, J. L. Decker, and A. L. Notkins. 1979. Immune interferon in the circulation of patients with autoimmune disease. N. Engl. J. Med. 301:5-8. 